http://dx.doi.org/10.5050/KSNVE.2012.22.5.413

$$
\begin{gathered}
\text { 은닉 마르코프 모델을 이용한 속도 변화가 있는 } \\
\text { 회전 기계의 상태 진단 기법 }
\end{gathered}
$$

\title{
Condition Monitoring of Rotating Machine with a Change in Speed Using Hidden Markov Model
}

\author{
장 미†.이 종 민*.황 요 하*.조 유 종**.송 재 복*** \\ M. Jang, J. M. Lee, Y. Hwang, Y. J. Cho and J. B. Song \\ (2011년 12월 2일 접수 ; 2012년 5월 7일 심사완료)
}

\begin{abstract}
Key Words : Hidden Markov Model(은닉 마르코프 모델), Rotating Machine(회전 기계), Condition Monitoring(상 태 진단), Compensation of Rotational Speed(회전 속도 보상)
\end{abstract}

\begin{abstract}
In industry, various rotating machinery such as pumps, gas turbines, compressors, electric motors, generators are being used as an important facility. Due to the industrial development, they make high performance(high-speed, high-pressure). As a result, we need more intelligent and reliable machine condition diagnosis techniques. Diagnosis technique using hidden Markov-model is proposed for an accurate and predictable condition diagnosis of various rotating machines and also has overcame the speed limitation of time/frequency method by using compensation of the rotational speed of rotor. In addition, existing artificial intelligence method needs defect state data for fault detection. hidden Markov model can overcome this limitation by using normal state data alone to detect fault of rotational machinery. Vibration analysis of step-up gearbox for wind turbine was applied to the study to ensure the robustness of diagnostic performance about compensation of the rotational speed. To assure the performance of normal state alone method, hidden Markov model was applied to experimental torque measuring gearbox in this study.
\end{abstract}

\section{1. 서 론}

회전 기계의 상태 진단은 대부분의 경우 시스템 의 진동 신호 분석을 통해 이루어져왔다. 기계 시스 템이 열화되고 있거나 문제가 생기면 가장 먼저 감 지되는 것이 진동 변화이고 더불어 온도, 압력 등 기계 상태의 여러 매개변수들이 변화하기 때문이다.

† 교신저자; 정회원, 고려대학교 기계공학부

E-mail : bbananamilks@korea.ac.kr

Tel : (02)958-6784, Fax : (02)958-6784

* 정회원, 한국과학기술연구원

** (주)두산모트롤

*** 고려대학교 기계공학부
진동 분석 방법에도 크게 피크값이나 제곱근 평균 값들을 비교하는 시간 영역 분석, 고속 푸리에 변환 이나 웨이블렛, 파워 스펙트럼을 통한 주파수 영역 분석으로 구분되는 신호 처리 기법과 인공 신경망 이나 퍼지 시스템, 전문가 시스템 등의 인공지능 알 고리즘을 접목한 지능형 기계 상태 진단법이 있다.

회전체의 상태 진단에 관한 최근의 연구 결과는 다음과 같다. Yang은 ${ }^{(1)}$ 인공 신경망과 서포트 벡터 머신을 이용해 냉장고의 왕복 압축기의 상태 진단 을 수행하였으며 $\mathrm{Chae}^{\text {는 }}{ }^{(2)}$ 스핀코터 시스템의 진동 저감을 위해 3 차원 모델링과 민감도 분석을 수행하 였다. Tomasz는(3) 스펙트럼 첨도를 이용하여 유성 
기어의 기어이 크랙을 검출하였고, Boulahbal은(4) 웨이블렛 지도의 크기와 위상을 통해 기어 시스템의 크랙 결함을 검출하였다.

이 논문에서는 $\mathrm{AR}$ (auto- regressive) 모델로 특징 벡터를 추출하고 은닉 마르코프 모델(hidden Markov model, HMM) 알고리즘을 적용하여 회전 속도가 변 동되는 회전체의 상태 진단 방법을 제시하였다. 파라 미터 기반의 시불변 계수(time invariant coefficients) 를 이용하는 시계열 모델링(AR)은 매우 짧은 시간 동안 변화하는 주파수를 감지하는 고시간 분해능을 특징으로 하여 초기 단계에 결함을 검출할 수 있는 장점이 있어 결함 진단 연구에 많이 사용된다. 최근 에는 $\mathrm{AR}$ 모델 기반의 LPC(linear predictive coding) 분석과 $\operatorname{EIV}$ (errors-in variables) 방법으로 추출한 특징 벡터를 신경회로망을 적용하여 결함 진단을 수행하는 연구가 수행되었다 ${ }^{(5)}$. 대부분의 연구에서 는 각기 다른 결함 데이터를 효과적으로 분류하는 목적으로 신경회로망을 이용하였지만 이 논문에서 는 $\mathrm{HMM}$ 을 이용하여 결함 데이터를 얻을 수 없는 상황에서도 적용이 가능한 진단 기법을 사용하였다. $\mathrm{HMM}$ 은 음성인식 분야에서 널리 쓰이고 있는 패턴 인식 알고리즘의 하나로 정확하고 강건한 진단 특 성과 결함 발생의 예측 성능을 보인다. $\mathrm{HMM}$ 을 기 계 상태 진단에 적용한 연구로 Bunks는(6) 헬리콥터 기어박스의 상태 진단에 연속 은닉 마르코프 모델 (CHMM)을 사용하였고 Ertunc는( ${ }^{(7)}$ 드릴링 작업 중 드릴 날의 마모 상태 진단에 $\mathrm{CHMM}$ 을 사용하였다. 국내에서 Lee와 Hwang 은 ${ }^{(8)}$ CHMM을 이용하여 선 반 가공 시 발생하는 채터 현상과 정하중 하에서의 저널베어링 마모를 진단하고 예측하는 연구를 수행 하였다.

기존의 회전 기계 상태 진단 연구에서 가장 널 리 사용되는 진단 기법은 고속 푸리에 변환을 통 한 진동 신호 처리이다. 그러나 대부분은 대상 시 스템의 회전 속도가 합리적인 수준이며 일정하게 고정되어 있다고 가정하였다. 정상적인 진동 신호 의 경우 속도 변화에 매우 민감하기 때문에 변동 속도에 대해서는 널리 사용되는 시간/주파수 분석 법을 적용할 수 없기 때문이다 ${ }^{(3)}$. 하지만 현실적으 로 상태 진단이 필요한 회전 기계의 경우 급격하 고 빠른 속도의 변동은 필수적으로 존재한다. 또한 지능형 기계 상태 진단에서 필수적으로 요구되는
다양한 결함에 대한 데이터를 얻는 것 역시 현실 에서는 매우 어렵다. 결함으로 인한 경제적 손실이 매우 크고 위험한 상황을 초래하기 때문이다. 이 논문에서는 기존의 회전체 상태 진단 기법의 한계 점을 개선하여 1) 가변하는 회전 속도를 적절히 보상하여 진단을 수행하고, 2) 현장에서 실제 결함 의 데이터 획득이 매우 어려운 문제점을 극복하는 시도로서 정상 상태의 데이터 만으로 시스템의 결 함을 진단할 수 있는 새로운 상태 진단 기법을 제 안한다.

$\mathrm{HMM}$ 을 이용한 기계 상태 진단은 매우 강인한 진단 특성을 보인다. 회전체 결함 신호의 패턴 인 식에 $\mathrm{HMM}$ 을 적용한 기존 연구에서는 특정 RPM 을 대표하는 모델로 어느 정도의 RPM 변화에 대 해서는 강건하게 진단하는 성능을 보였으나 큰 변 화에 대해서는 정확한 진단이 어려웠다 ${ }^{(9)}$. 이 연구 에서는 회전 속도를 보상하기 위해서, 일반적인 동 일 시간 간격의 샘플링이 아닌 동일 회전각 간격 의 샘플링을 통해 회전 기계의 진동 신호를 측정 하였다. 또한 각 RPM에서 측정한 데이터를 이용 하여 하나의 RPM 통합 $\mathrm{HMM}$ 을 모델링 하였다. 따라서 회전 속도의 변동 범위가 넓은 회전 기계 에 대해 RPM 통합 $\mathrm{HMM}$ 을 적용하여 회전 속도의 변화를 보상한 회전체 상태 진단을 수행하였으며 기존 진단 기법들의 문제점을 해결하여 정확한 상 태 진단이 가능함을 실험을 통하여 입증하였다. 실 례로 회전 속도가 급격히 바뀌지만 결함 데이터를 얻을 수 없는 풍력발전기 증속기 상태 진단의 경 우에도 정확한 상태 진단을 위해, 정상 상태 용접 데이터만을 이용하여 용접 결함 상태를 정확히 진 단하는 Lee와 Hwang의 ${ }^{(10)}$ 연구를 회전체의 상태 진단에 적용하였다. 또한 기어박스의 결함 검출에 이 연구를 적용하여 정상 상태 $\mathrm{HMM}$ 의 진단 결과

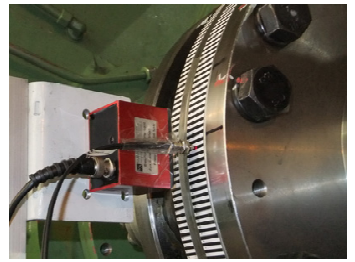

(a)

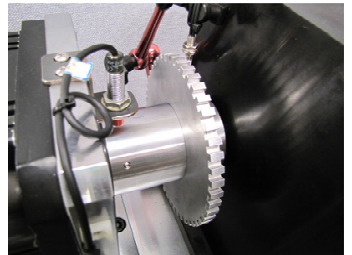

(b)
Fig. 1 (a) grid, and (b) gear for trigger signal 
값의 변화로 정상 기어박스와 결함 기어박스를 정 확하게 구분하였다.

\section{2. 속도 변화가 있는 회전체의 상태 진단}

\section{1 동일 회전각 간격의 신호 측정}

일반적으로 신호의 측정은 샘플링 주파수를 정하 여 측정하는 데 이때 샘플링 주파수는 동일한 시간 동안 몇 번의 샘플링을 할 것인지를 말한다. 하지만 이 방식으로 회전체의 진동 신호를 측정할 경우 회 전 속도에 따라 한 바퀴당 측정되는 데이터의 수가 달라지게 된다. 동일한 시스템이 저속으로 회전할 때 의 한 회전당 측정 횟수가 고속으로 회전을 하면 더 줄어드는 것이다. 이에 기존의 연구에서는 회전체의 상태 진단을 일정한 속도 조건에 대해서만 적용해야 했다. 이 연구에서는 진동 신호 측정을 위해 동일 시 간 간격의 샘플링이 아닌 동일 회전각 간격의 샘플 링을 수행하였다. Fig. 1의 (a)와 같이 측정할 시스템 출력축의 커플링 플랜지(coupling flange)에 트리거 (trigger) 신호로 사용하기 위한 그리드(grid)를 제작 하였다. 그리드에 직각으로 설치된 광센서를 통해 회 전 속도에 관계없이 한 회전당 동일한 펄스가 발생 되며 펄스의 라이징 엣지(rising edge)에서 시스템의 진동 신호를 샘플링한다. 트리거용 펄스 신호는 대상 시스템의 측정 환경에 따라 Fig. 1의 (b)와 같이 회전 축에 톱니를 설치하여 얻을 수도 있다.

\section{2 회전 속도 보상의 RPM 통합 모델}

회전체의 진동 신호는 속도에 매우 민감하다. Zhang과 Zhan이 수행한 기존의 연구 결과를 살펴 보면 ${ }^{(11,12)}$ 한 가지 조건의 RPM을 선정하거나 특정 $\mathrm{RPM}$ 을 선정하여 실험을 수행하였다. 그러나 한 가 지 이상의 회전 속도로 실험을 수행한 연구에서도 각각의 $\mathrm{RPM}$ 에 대해서만 상태 진단을 수행하였을 뿐 변하는 회전 속도나 다른 조건의 회전 속도에 대한 상태 진단은 이루어지지 않았다. 하지만 실제 산업 현장에서 대부분의 회전 기계는 회전 속도의 변화가 생기며 풍력발전기와 같이 회전 속도와 시 스템에 가해지는 부하의 변동이 매우 크고 급격한 시스템도 존재한다. 특히 풍력발전기의 경우 보수가 어렵고 결함이 생겼을 경우 매우 큰 사고를 유발하 기 때문에 정확한 상태 진단이 요구된다. 이 연구에
서는 특정 RPM 조건을 선정하여 신호를 측정하고 이 데이터를 모두 통합한 통합 모델을 만듦으로써 회전 속도를 보상한 상태 진단을 수행한다.

\section{3 정상 상태 은닉 마르코프 모델을 이용한 상태 진단}

현재 대부분의 지능형 상태 진단 기법들은 정상 상태를 대표하는 신호와 결함 상태를 대표하는 신 호들을 비교하여 모델이나 판단기준을 만들어 대상 시스템의 상태를 진단한다. HMM은 확률값들의 역 수나 곱, 합으로 연산이 이루어지기 때문에 시스템 의 상태 변화에 따른 진단 결과가 매우 크게 달라 진다. 또한 정상 모델에 대한 상태 진단의 결과와 결함 모델에 대한 상태 진단 결과의 차이가 매우 크게 나타난다 ${ }^{(6)}$. 따라서 $\mathrm{HMM}$ 을 이용하여 회전체 의 상태 진단을 수행하면 결함 모델없이 정상 모델 에 대한 진단 결과의 변화 추이만을 살펴봄으로써 대상 시스템이 정상 상태인지, 결함이 생기고 있는 지, 이미 생겼는지의 추정이 가능하다. 기계 상태 진단을 위한 $\mathrm{HMM}$ 은 크게 트레이닝과 진단의 두 가지 과정을 거쳐 결과를 얻는다. 이 연구에서는 기 계의 상태를 나타내는 연속적인 진동 신호를 모델 링해야 하므로 $\mathrm{CHMM}$ 을 이용하여 회전 기계의 상 태 진단을 수행하였다. HMM에 사용할 특징 벡터 들은 대상 시스템에서 측정한 신호에서 시계열 데 이터의 주기성을 모형화하는 $\mathrm{AR}$ (auto-regressive) 모델의 계수를 신호의 특징 벡터로 사용하였다.

기계 상태 진단을 위한 $\mathrm{CHMM}$ 을 다음과 같이 정의한다. 진단하고자 하는 상태의 시계열 데이터에 서 $D$ 차원 특징 벡터를 추출한 전처리 과정 이후에 는 이를 시간 순으로 나열하여 $K$ 개의 관측 벡터열 을 이룬다. $D$ 차원 특징 벡터 $T_{k}$ 개를 $K$ 개의 관측 벡터열로 나타내면 식(1)과 같다. 여기서 $T_{k}$ 가 $k$ 번째 관측 벡터열에서 관측한 횟수라고 하면 $k$ 번째 관측 벡터열, $O^{k}$ 는 식 (2), (3)과 같다.

$$
\begin{aligned}
& O=\left\{O^{1}, O^{2}, \ldots, O^{K}\right\} \\
& O^{k}=\left\{\overrightarrow{o_{1}^{k}}, \overrightarrow{o_{2}^{k}}, \ldots, \overrightarrow{o_{T_{k}}^{k}}\right\} \\
& \overrightarrow{o_{t}^{k}}=\left[\begin{array}{llll}
o_{t 1}^{k} & o_{t 2}^{k} \ldots & o_{t D}^{k}
\end{array}\right]^{T}
\end{aligned}
$$

또한 관측 벡터열이 관측될 수 있는 각각 다른 
$\mathrm{N}$ 개의 상태(state)들은 식 (4)로 구성된다.

$$
S=\left\{S_{1}, S_{2}, \ldots, S_{N}\right\}
$$

각 상태에서의 관측 확률 밀도에 있는 평균의 수 에 해당하는 혼합물(mixture)의 수 $M$ 은 다음 식 (5)와 같다.

$$
X=\left\{\begin{array}{llll}
x_{11} & x_{12} & \cdots & x_{1 M} \\
x_{21} & x_{22} & \cdots & x_{2 M} \\
\cdots & \cdots & \cdots & \cdots \\
x_{N 1} & x_{N 2} & \cdots & x_{N M}
\end{array}\right\}
$$

이러한 상태 $S$ 와 관측 벡터열 $O$ 사이에는 통계적 특성을 갖는데 이를 $\mathrm{CHMM}$ 으로 식 (6)과 같이 나 타낸다.

$$
\lambda_{c}=\{\vec{\pi}, A, \mu, U, C\}
$$

여기서 초기상태분포 벡터, $\vec{\pi}$ 는 식 (7)과 같다.

$$
\vec{\pi}=\left[\pi_{1} \pi_{2} \cdots \pi_{N}\right]^{T}
$$

각 성분은 다음의 식 (8)의 조건을 만족하며 $n$ 번 째 상태가 첫 번째 상태일 확률이다.

$$
\pi_{n}=\mathrm{P}\left[q_{1}=s_{n}\right] \geq 0, \sum_{n=1}^{N} \pi_{i}=1
$$

상태천이확률분포 행렬, $A$ 의 각 성분은 $i$ 번째 상 태에서 $j$ 번째 상태로 천이할 확률이며 다음의 식 (9), (10)의 조건을 만족한다.

$$
\begin{gathered}
A=\left[\begin{array}{cccc}
a_{11} & a_{12} & \cdots & a_{1 N} \\
a_{21} & a_{22} & \cdots & a_{2 N} \\
\cdots & \cdots & \cdots & \cdots \\
a_{N 1} & a_{N 2} & \cdots & a_{N N}
\end{array}\right] \\
a_{i j}=\mathrm{P}\left[q_{t+1}=s_{j} \mid q_{t}=s_{i}\right] \geq 0, \\
\sum_{j=1}^{N} a_{i j}=1 \quad \forall i=1,2, \ldots, N
\end{gathered}
$$

평균벡터(mean vector) 집합, $\mu$ 는 식(11)과 같다. 각 성분은 $n$ 번째 상태의 $m$ 번째 혼합물 $\left(x_{n m}\right)$ 에서의
평균 벡터이다.

$$
\begin{aligned}
& \mu=\left[\begin{array}{lllll}
\overrightarrow{\mu_{11}} & \overrightarrow{\mu_{12}} & \cdots & \overrightarrow{\mu_{1 M}} \\
\overrightarrow{\mu_{21}} & \underset{\mu_{22}}{\longrightarrow} & \cdots & \overrightarrow{\mu_{2 M}} \\
\cdots & \cdots & \cdots & \cdots \\
\overrightarrow{\mu_{N 1}} & \overrightarrow{\mu_{N 2}} & \cdots & \overrightarrow{\mu_{N M}}
\end{array}\right] \\
& \overrightarrow{\mu_{n m}}=\left[\begin{array}{llll}
\mu_{n m, 1} & \mu_{n m, 2} & \cdots & \mu_{n m, D}
\end{array}\right]
\end{aligned}
$$

공분산행렬(covariance matrix) 집합, $U$ 는 다음의 식 (12)와 같다. 각 성분은 $n$ 번째 상태의 $m$ 번째 혼 합물에서의 공분산행렬이다.

$$
\begin{gathered}
U=\left[\begin{array}{cccc}
U_{11}, & U_{12}, & \cdots & U_{1 M} \\
U_{21}, & U_{22}, & \cdots & U_{2 M} \\
\cdots & \cdots & \cdots & \cdots \\
U_{N 1}, & U_{N 2}, \cdots & U_{N M}
\end{array}\right] \\
U_{n m}=\left[\begin{array}{cccc}
u_{n m, 11} & u_{n m, 12} & \cdots & u_{n m, 1 D} \\
u_{n m, 21} & u_{n m, 22} & \cdots & u_{n m, 2 D} \\
\cdots & \cdots & \cdots & \cdots \\
u_{n m, D 1} & u_{n m, D 2} & \cdots & u_{n m, D D}
\end{array}\right]
\end{gathered}
$$

혼합물 이득(mixture gain) 행렬, $C$ 는 식(13)과 같다.

$$
C=\left[\begin{array}{llll}
c_{11} & c_{12} & \cdots & c_{1 N} \\
c_{21} & c_{22} & \cdots & c_{2 N} \\
\cdots & \cdots & \cdots & \cdots \\
c_{N 1} & c_{N 2} & \cdots & c_{N N}
\end{array}\right]
$$

각 성분은 $n$ 번째 상태의 $m$ 번째 혼합물의 이득 이며 다음의 식 (14)의 조건을 만족한다.

$$
\begin{aligned}
& c_{n m} \geq 0, \sum_{m=1}^{M} c_{n m}=1 \\
& \forall n=1,2, \ldots, N
\end{aligned}
$$

위와 같이 $\mathrm{CHMM}$ 이 정의되면 상태 $s_{n}$ 에서 관측 벡터 $\overrightarrow{o_{t}^{k}}$ 가 관측될 확률밀도함수 $b_{t, n}^{\bar{k}}$ 는 식 (15)와 같 다. 이때 혼합물 $x_{n m}$ 에서 관측벡터 $\overrightarrow{o_{t}^{k}}$ 가 관측될 확 률밀도함수 $b_{t, n m}^{k}$ 는 Gaussian 밀도함수이다.

트레이닝 과정에서는 초기값으로 배정된 $\mathrm{CHMM}$ 의

$$
b_{t, n}^{\widetilde{k}}=\sum_{m=1}^{M} c_{n m} \cdot b_{t, n m}^{\bar{k}}=\sum_{m=1}^{M} c_{n m} \cdot \frac{\exp \left(-0.5 \cdot\left(\overrightarrow{o_{t}^{k}}-\overrightarrow{u_{n m}}\right)^{T} \times U_{n m}^{-1} \times\left(\overrightarrow{o_{t}^{k}}-\overrightarrow{u_{n m}}\right)\right)}{\sqrt{(2 \pi)^{D} \cdot\left|U_{n m}\right|}}
$$


파라미터들을 구간별 $k$-평균 군집화(segmental k-means clustering)방법과 Baum-Welch 알고리즘을 이용하여 정확한 값으로 추정하여 최적의 $\mathrm{CHMM}$ 을 모델링 한다.

진단 과정에서는 진단하고자 하는 시스템으로부터 시계열 데이터를 측정한 후 트레이닝 과정에서 사용 된 특징 추출 방법과 동일한 $\mathrm{AR}$ 모델로 특징 벡터

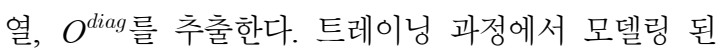
모든 CHMM, $\lambda_{c i}$ 에 대해 식(16)과 같이 얻어진 특 징 벡터열이 관측될 로그우도(log-likelihood)를 계산 하여 가장 큰 값을 갖는 $\mathrm{CHMM}$ 의 상태가 현재 시스 템의 상태라고 진단한다.

$$
\text { Index of fault }=\underset{\forall i}{\max \log }\left(\mathrm{P}\left[O^{\text {diag }} \mid \lambda_{c i}\right]\right)
$$

이 논문에서는 트레이닝 과정에서 정상 상태를 대표하는 데이터를 이용하여 정상 상태 $\mathrm{HMM}$ 을 학 습시켰으며 그 진단 결과인 로그우도의 변화 추이 를 감시하여 회전 기계의 상태 및 결함을 진단한다.

\section{4 제안한 상태 진단 기법}

이 논문에서 제안하는 회전 기계 상태 진단의 전 체적인 절차는 Fig. 2 와 같다. 트레이닝 과정에서는 정속으로 회전하는 정상 상태의 회전 기계에서 동 일 회전각 간격의 진동 신호를 측정한다. $\mathrm{AR}$ 모델 의 계수로 특징 벡터를 추출하고 정상 상태 $\mathrm{RPM}$ 통합 $\mathrm{HMM}$ 을 트레이닝 한다. 진단 과정에서는 회 전 속도가 변하는 진단 대상 회전 기계에서 동일 회전각 간격의 진동 신호를 측정한다. $\mathrm{AR}$ 모델의 계수로 특징 벡터를 추출하고 정상 상태 RPM 통합 $\mathrm{HMM}$ 에 대한 로그우도를 계산한다. 진단 결과가 0 이상의 변동폭이 작은 일정한 크기의 값을 유지하

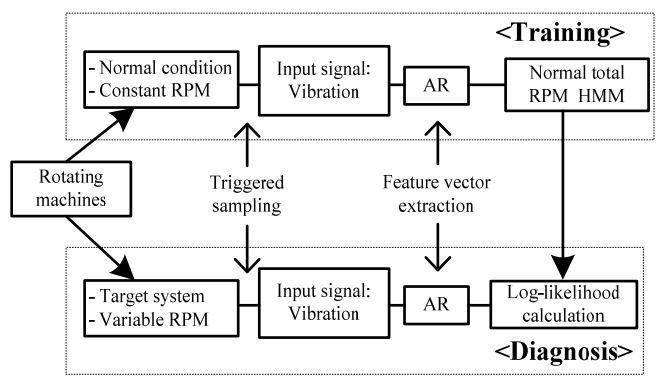

Fig. 2 Diagram of condition monitoring system
다가 낮아지면 진단 대상 시스템에 결함이 생겼음 을 의미한다.

\section{3. 회전체의 상태 진단}

\section{1 기어박스의 결함 검출}

이 논문에서 제안한 기법의 검증을 위해 회전 토 크 측정장비의 증속 기어박스 상태 진단을 $\mathrm{HMM}$ 을 사용하여 수행하였다. 이 측정장비의 구성은 Fig. 3 과 같이 좌측 상단의 모터의 회전력이 감속 기어박 스, 하부 회전축을 거쳐 우측에 있는 증속 기어박스 에 전달되는 시스템이다. 증속 기어박스와 감속 기 어박스는 동일하며 3 개의 축을 갖는 2 단 기어박스 로 기어비는 9 이다. 상태 진단을 위한 대상 시스템 은 증속 기어박스이며 출력축 상부에 가속도 센서 를 설치하여 기어박스의 횡방향 진동 신호를 측정 하였다. 기존의 선행 연구에서는 특정 RPM에서 측 정된 데이터만을 이용하기 때문에 회전 속도가 변 동되는 회전 기계는 정확한 상태 진단이 어려웠다. 이를 확인하기 위하여 특정 RPM을 선정하여 실험 을 수행하였다. 회전 속도의 변화에 무관하게 한 회 전당 일정한 개수의 진동 신호의 측정을 위하여 Fig. 1(b)와 같은 톱니를 제작하여 출력축의 1 회전 당 48 번 측정하였다. 모델링에 필요한 데이터는 기 어박스를 $500,900,1500 \mathrm{RPM}$ 으로 회전시켜 진동 신호를 측정하였다. 각 $\mathrm{RPM}$ 에서 측정한 데이터를 이용하여 해당 RPM HMM을 트레이닝 하였다. 상 태 진단은 트레이닝 RPM과 같은 RPM으로 기어박 스를 회전시켜 수행하였다. Fig. 4는 1500 RPM으로 회전하는 기어박스의 상태 진단 결과이다. Fig. 4의 (a)는 기어박스의 횡방향 진동 신호이고 (b)는 상태

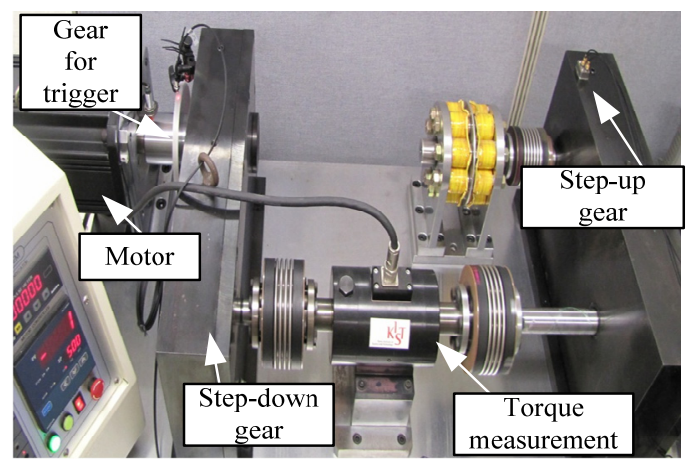

Fig. 3 Photo of torque measuring system 
진단 결과이다. 점선은 $1500 \mathrm{RPM}$ 으로 회전할 때의 데이터로 만든 $1500 \mathrm{RPM} \mathrm{HMM}$ 의 진단 결과이며 다른 RPM HMM의 진단 결과보다 큰 값을 나타낸 다. 하지만 그 외의 진단 결과는 0 이하의 음수로 매우 작은 값을 나타낸다. 진단 결과가 음수로 나타 나는 것은 확률값의 차이가 매우 크기 때문에 적절 한 그래프 표시를 위하여 로그스케일( $\log$-scale)로 나타내었기 때문이다. 위의 실험 결과에서 해당 RPM 데이터로 모델링 하지 않은 HMM은 기어박 스의 상태를 정확히 진단하지 못하는 것을 확인할 수 있다. Fig. 5는 $500 \mathrm{RPM}$ 으로 회전하는 기어박스 의 상태 진단 결과이며 $500 \mathrm{RPM} \mathrm{HMM}$ 의 진단 결 과인 실선이 가장 큰 값을 나타낸다. 따라서 단순히 동일 회전각 간격의 신호 측정만으로는 $\mathrm{HMM}$ 알고

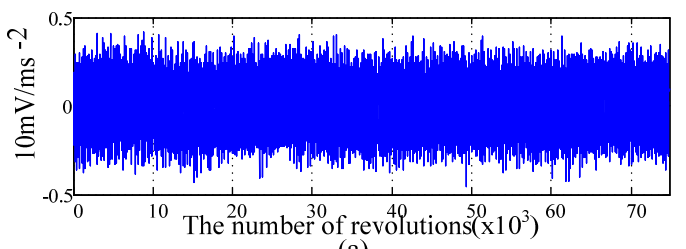

(a)

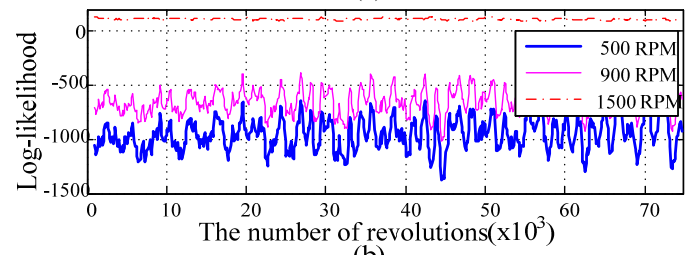

(b)

Fig. 4 Gearbox at 1500 RPM: (a) vibration signal, and (b) diagnosis result

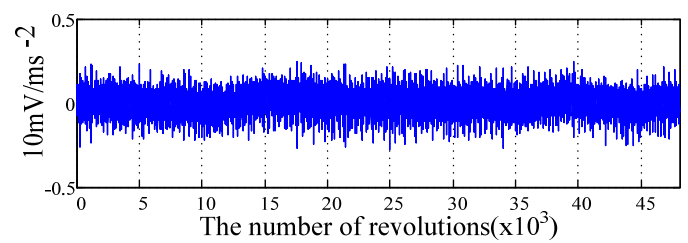

(a)

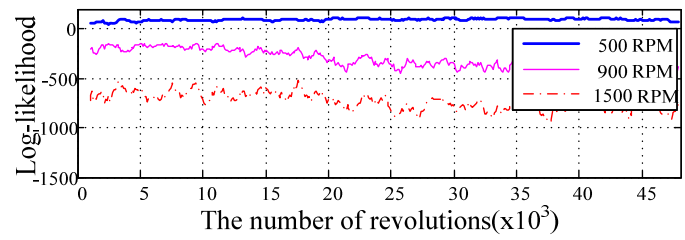

(b)

Fig. 5 Gearbox at 500 RPM: (a) vibration signal, and (b) diagnosis result
리즘을 이용해도 회전 속도가 크게 변동하는 회전 체의 정확한 상태 진단이 어렵다. 회전 속도를 보상 하는 상태 진단은 동일 회전각 간격의 진동 신호 측정과 적절한 간격을 가진 $\mathrm{RPM}$ 에 대한 측정 신호 를 바탕으로 RPM 통합 HMM을 만들어 일정한 범 위 내에서 속도가 변하며 운전하는 회전체의 상태 를 진단해야 한다.

이 연구 내용인 회전 속도 보상이 이루어진 상태 진단 기법의 진단 성능을 입증하기 위하여 인위적 으로 결함을 가공하여 실험을 수행하였다. 인위적 결함은 기어 결함에서 중요도가 높은 이면 피로 (surface fatigue) 결함을 재현하기 위하여 Fig. 6의 (b)와 같이 하나의 기어이 맞물림 면에 대해서 이끝 원의 중심에서 이 뿌리원까지 빗금 친 부분을 절삭 가공하였다. 모델링에 필요한 데이터는 기어박스의 진동 신호를 $500 \mathrm{RPM}$ 부터 $1500 \mathrm{RPM}$ 까지 200 $\mathrm{RPM}$ 간격으로 측정하여 각 $\mathrm{RPM}$ 에서의 데이터로 $\mathrm{RPM}$ 통합 $\mathrm{HMM}$ 을 트레이닝 하였다. RPM 통합 $\mathrm{HMM}$ 은 진단하고자 하는 상태의 샘플 데이터에 각 $\mathrm{RPM}$ 에서의 데이터를 모두 포함하여 트레이닝 한 다. 동일 회전각 간격으로 신호 측정을 하여 회전 속도가 달라도 동일한 조건으로 측정된 신호이다. 따라서 하나의 HMM으로 트레이닝이 가능하다.

실험은 정상 상태의 기어박스와 기어이에 결함이 있는 결함 상태 기어박스에 대해 동일한 조건으로 수행되었고 각각의 데이터로 정상 상태의 RPM 통 합 $\mathrm{HMM}$ 과 결함 상태의 RPM 통합 $\mathrm{HMM}$ 을 트레 이닝 하였다. 정상 상태 기어박스를 $500,700,900$, $1100,1300,1500 \mathrm{RPM}$ 으로 회전시켜 측정한 데이 터를 통합하여 정상 상태의 RPM 통합 $\mathrm{HMM}$ 을 학 습시켰다. 결함 기어박스의 경우도 같은 방법으로 결함 상태의 RPM 통합 $\mathrm{HMM}$ 을 만들고 기어박스 의 진동 신호를 바탕으로 상태를 진단하여 결함이 있는지를 검출하였다. Fig. 7은 기어박스가 1500 $\mathrm{RPM}$ 으로 회전할 때 정상 상태의 기어박스의 진동 신호와 그 진단 결과이다. Fig. 7의 (b)를 보면 점선 의 정상 상태 통합 $\mathrm{HMM}$ 의 진단 결과 값이 더 크 게 나타나고 결함 상태 통합 $\mathrm{HMM}$ 의 진단 결과는 매우 작은 값을 나타낸다. 따라서 진단한 시스템을 정상 상태로 판정하였다. Fig. 8은 결함 기어박스가 $1500 \mathrm{RPM}$ 으로 회전할 때의 그래프이다. Fig. 8의 (b)를 보면 실선의 결함 상태 통합 $\mathrm{HMM}$ 의 진단 
결과 값이 더 큰 값을 나타낸다. 즉, 시스템에 결함 이 있는 것을 정확하게 진단하였다. 상태 진단에 $\mathrm{RPM}$ 통합 $\mathrm{HMM}$ 을 사용하였기에 $1500 \mathrm{RPM}$ 에서 의 데이터 외에 $500,700,900,1100,1300 \mathrm{RPM}$ 에 대해서도 진단을 수행하였으며 Fig. 9는 정상 상 태의 증속 기어박스가 $900 \mathrm{RPM}$ 으로 회전할 때의

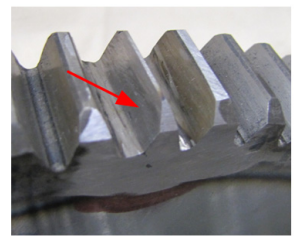

(a)

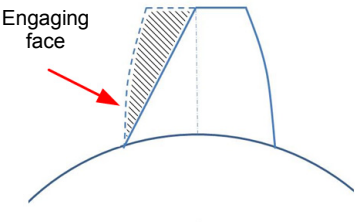

(b)
Fig. 6 Artificial gear fault: (a) photo, and (b) cross-section diagram

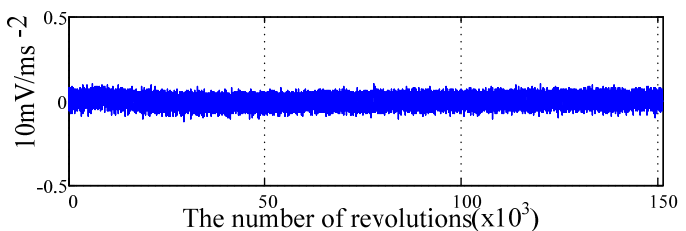

(a)

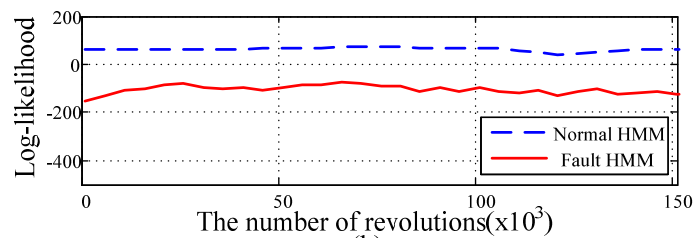

(b)

Fig. 7 Normal gearbox at 1500 RPM: (a) vibration signal, and (b) diagnosis result

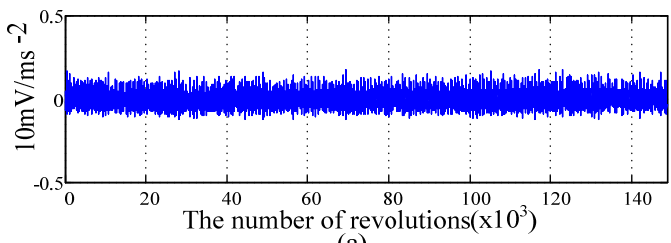

(a)

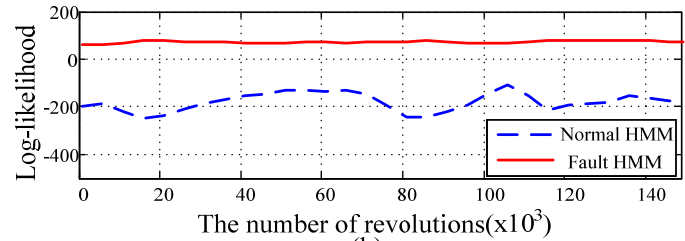

(b)

Fig. 8 Faulty gearbox at 1500 RPM: (a) vibration signal, and (b) diagnosis result
진단 결과이다. Fig. 9의 (b)에서 점선의 정상 상태 통합 $\mathrm{HMM}$ 의 진단 결과 값이 더 큰 값을 나타낸 다. 따라서 대상 시스템을 정상으로 판단하였다.

Fig. 10은 결함 기어박스가 $900 \mathrm{RPM}$ 으로 회전할 때의 진단 결과이며 Fig. 10 의 (b)에서 실선의 결함 상태 통합 $\mathrm{HMM}$ 의 결과가 더 큰 값을 나타낸다. 위의 실험 결과들(Figs. 7 10)에서 정상 상태 통합 $\mathrm{HMM}$ 의 진단 결과 값만을 확인하면 정상 기어박 스의 진단 결과는 항상 0 이상의 큰 값을 나타내 고 결함 기어박스의 경우에는 음수의 작은 값을 나타낸다. 그래프가 로그 스케일로 표현되었기 때 문에 양수의 값과 대수적으로 적은 차이일지라도 실제 확률값의 차이는 매우 크다. 위의 진단 결과 에서 정상 $\mathrm{HMM}$ 의 진단 결과만 존재할 때 로그 우도가 0 이상의 양수 값을 유지하다 음수로 값이

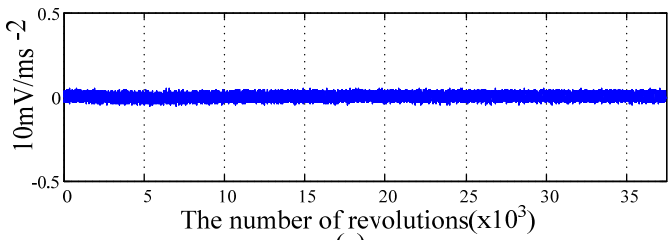

(a)

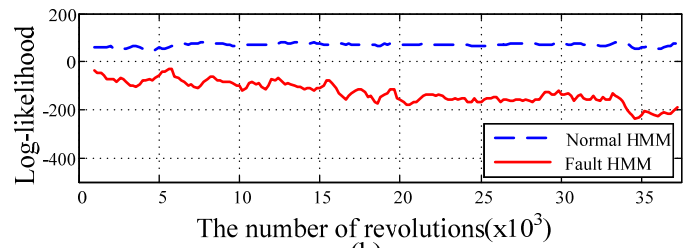

(b)

Fig. 9 Normal gearbox at 900 RPM: (a) vibration signal, and (b) diagnosis result

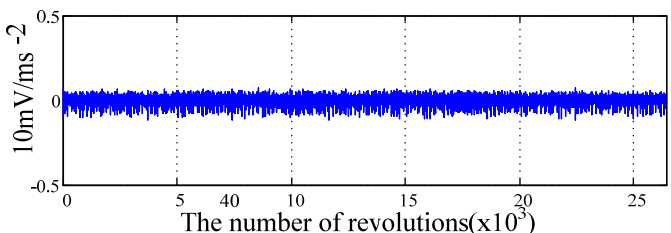

(a)

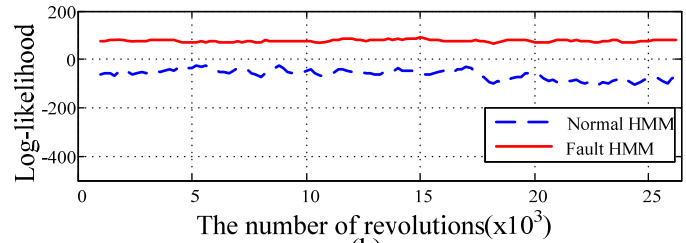

(b)

Fig. 10 Faulty gearbox at 900 RPM : (a) vibration signal, and (b) diagnosis result 


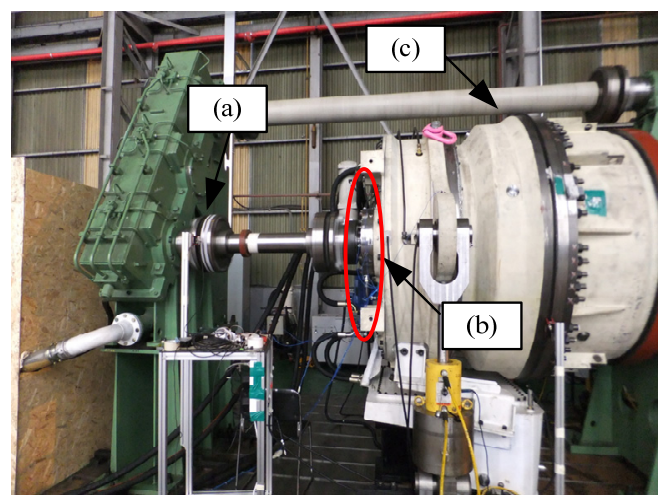

Fig. 11 Experiment system: (a) grid for trigger, (b) accelerometers, and (c) step-up gear

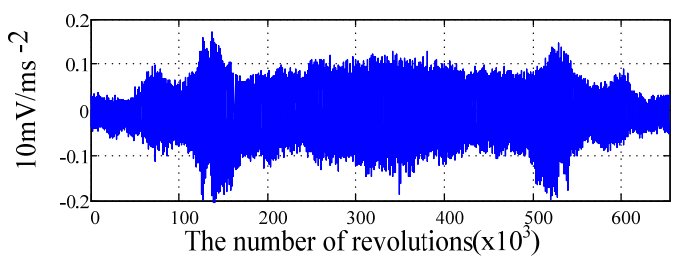

(a)

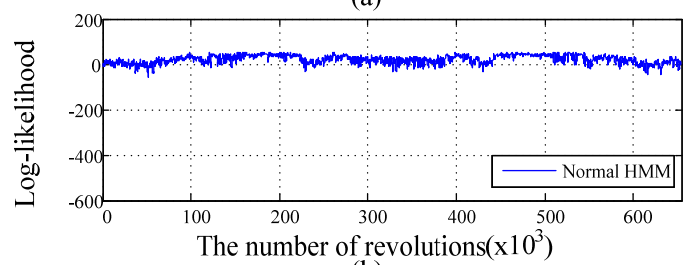

(b)

Fig. 12 Gearbox for wind turbine in running up and down: (a) vibration signal, and (b) diagnosis result

떨어진다면 이를 통해 기어박스에 결함이 생겼음 을 판단할 수 있다. 따라서 실제 결함 데이터를 얻을 수 없어 결함 $\mathrm{HMM}$ 을 만들 수 없는 산업 현장에서는 정상 상태 통합 $\mathrm{HMM}$ 의 진단 결과 추이만을 확인하여 기계 상태의 결함 검출이 가 능하다.

\section{2 풍력발전기 증속기의 실시간 상태 진단}

이 연구에서는 회전 속도를 보상하여 $3 \mathrm{MW}$ 급 풍 력발전기 증속기의 상태를 진단하였다. 회전 속도를 보상하는 상태 진단은 회전 속도에 무관한 진동 신 호 측정과 $\mathrm{RPM}$ 통합 $\mathrm{HMM}$ 으로 수행한다. 특정 $\mathrm{RPM}$ 에 대한 측정 신호를 바탕으로 RPM 통합 $\mathrm{HMM}$ 을 만들어 일정한 범위 내에서 속도가 변하며
운전하는 증속기의 상태를 진단한다. 증속기는 속도 에 따라 적절히 변하는 부하가 연결된 상태에서 운 전되며 RPM 통합 $\mathrm{HMM}$ 을 만들기 위하여 778 , $1082,1329,1462 \mathrm{RPM}$ 에서 정속 회전하여 진동 신 호를 측정하였다.

측정된 데이터는 시계열 데이터의 주기성을 모형 화하는 $\mathrm{AR}$ (auto-regressive) 모델의 계수를 신호의 특징 벡터로 사용하였으며 정상 상태를 대표하는 정상 $\mathrm{HMM}$ 으로 트레이닝 하였다. 상태 진단을 위 한 실험에서는 증속기를 $745 \mathrm{RPM}$ 에서 $1462 \mathrm{RPM}$ 까지 속도를 증가시키고 다시 $745 \mathrm{RPM}$ 으로 속도를 낮추며 진단용 데이터를 측정하였다. Fig. 12에서 (a)는 증속기의 진동 신호이고 (b)는 상태 진단 결 과이다. 실선은 총 4 가지 $\mathrm{RPM}$ 에서 측정한 데이터 로 트레이닝 한 RPM 통합 $\mathrm{HMM}$ 의 진단 결과를 나타낸다. 증속기를 $745 \mathrm{RPM}$ 에서 $1462 \mathrm{RPM}$, 다시 $745 \mathrm{RPM}$ 으로 운전시키는 동안 RPM 통합 $\mathrm{HMM}$ 의 진단 결과는 모두 0 이상의 값을 나타낸다. 따라서 현재 진단하고 있는 시스템이 정상 상태임을 정확 하게 진단하였다. 증속기에 결함이 생긴다면 3.1절 의 실험 결과(Figs. 7 10)에서 정상 $\mathrm{HMM}$ 의 진단 결과와 같이 Fig. 12의 (b)에서 진단 결과가 음수의 값을 나타낼 것이다.

\section{4. 결 론}

이 연구에서는 기존의 회전체 상태 진단 시스템 의 문제점을 해결하는 시도로서 RPM 통합 HMM 을 이용한 회전 기계 상태 진단 기법을 소개하였 다. 동일 시간 간격의 측정이 아닌 동일 회전각 간 격으로 진동 신호를 측정하여 여러 개의 특정 RPM 데이터를 하나의 RPM 통합 HMM으로 트레 이닝 하였다. 또한 시스템의 상태 변화에 따른 진 단 결과가 매우 크게 달라지는 $\mathrm{HMM}$ 알고리즘의 장점을 회전 기계의 상태 진단에 적용하였다. 결함 데이터를 얻을 수 없는 시스템의 상태 진단에 정 상 상태 데이터만을 이용하여 모델링 한 정상 상 태 RPM 통합 HMM을 적용하면 시스템의 상태 변 화에 따라 진단 결과인 로그우도가 크게 변한다. 따라서 로그우도의 변화를 통해 회전 기계의 결함 검출 및 상태 진단이 가능하다. 이 논문에서 제안 한 기법은 회전 속도의 변화에도 강건한 상태 진 
단 성능을 확인하기 위해 풍력발전기 증속기 모니 터링에 적용하였다. 또한 정상 상태 RPM 통합 $\mathrm{HMM}$ 만을 이용한 회전 기계의 결함 검출 성능을 인위적으로 결함을 가공한 기어박스 상태 진단 실 험을 통해서 입증하였다.

\section{후 기}

이 연구는 2009년도 지식경제부의 재원으로 한국 에너지 기술평가원(KETEP)의 지원을 받아 수행한 연구 과제입니다(No. 2009T100200095).

\section{참 고 문 헌}

(1) Yang, B. S., Hwang, W. W., Kim, D. J. and Tan, A., 2005, Condition Classification of Small Reciprocating Compressor for Refrigerators using Artificial Neural Networks and Support Vector Machines, Mechanical Systems and Signal Processing, Vol. 19, No. 2, pp. 371 390.

(2) Chae, H. C., Ryu, I. C. and Han, C. S., 2003, 3-Dimensional Modeling and Sensitivity Analysis for Vibration Reduction of the Spin-coater System(in Korean), Journal of the Korean Society of Precision Engineering. Vol. 20, No. 2, pp. 209 217.

(3) Tomasz, B. and Robert, B. R., 2009, Application of Spectral Kurtosis for Detection of a Tooth Crack in the Planetary Gear of a Wind Turbine, Mechanical Systems and Signal Processing, Vol. 23, pp. 1352 1365.

(4) Boulahbal, D., Golnaraghi, M. F. and Ismail, F., 1999, Amplitude and Phase Wavelet Maps for the Detection of Cracks in Geared Systems, Mechanical Systems and Signal Processing, Vol. 13, pp. $423 \sim 436$.

(5) Han, H. S., Cho, S. J. and Chong, U. P.,
2011, Neural-network-based Fault Detection and Diagnosis Method Using EIV(errors-in variables), Journal of Sound and Vibration, Vol. 21, No. 11, pp. $1020 \sim 1028$.

(6) Bunks, C., McCarthy, D. and Al-Ani, T., 2000, Condition-based Maintenance of Machine Using Hidden Markov Models, Mechanical Systems and Signal Processing, Vol. 14, pp. 597 612.

(7) Ertunc, H. M., Loparo, K. A. and Ocak, H., 2001, Tool Wear Condition Monitoring in Drilling Operations Using Hidden Markov Models, International Journal of Machine Tools and Manufacture, Vol. 41, pp. 1363 1384.

(8) Lee, J. M., Kim, S. J., Hwang, Y. and Song, C. S., 2004, Diagnosis of Mechanical Fault Signals Using Continuous Hidden Markov Model, Journal of Sound and Vibration. Vol. 276, pp. 1065 1080.

(9) Lee, J. M., Kim, S. J., Hwang, Y. and Song, C. S., 2003, Pattern Recognition of Rotor Fault Signal Using Hidden Markov Model, Journal of Korean Society of Mechanical Engineering, Vol. 27, No. 11, pp. 1864 1872.

(10) Lee, J. M. and Hwang, Y., 2011, New Machine Condition Diagnosis Method Not Requiring Fault Data Using Continuous Hidden Markov Model, Transactions of the Korean Society for Noise and Vibration Engineering, Vol. 21, No. 2, pp. 146 153.

(11) Zhang, G., Ge, Y., Fang, K. and Liang, Q., 2008, An Intelligent Monitor System for Gearbox Test, Communications in Computer and Information Science, Vol. 15, Part. 7, pp. 252 259.

(12) Zhan, Y. and Makis, V., 2006, A Robust Diagnostic Model for Gearboxes Subject to Vibration Monitoring, Journal of Sound and Vibration, Vol. 290, No. 3-5, pp. 928 955. 